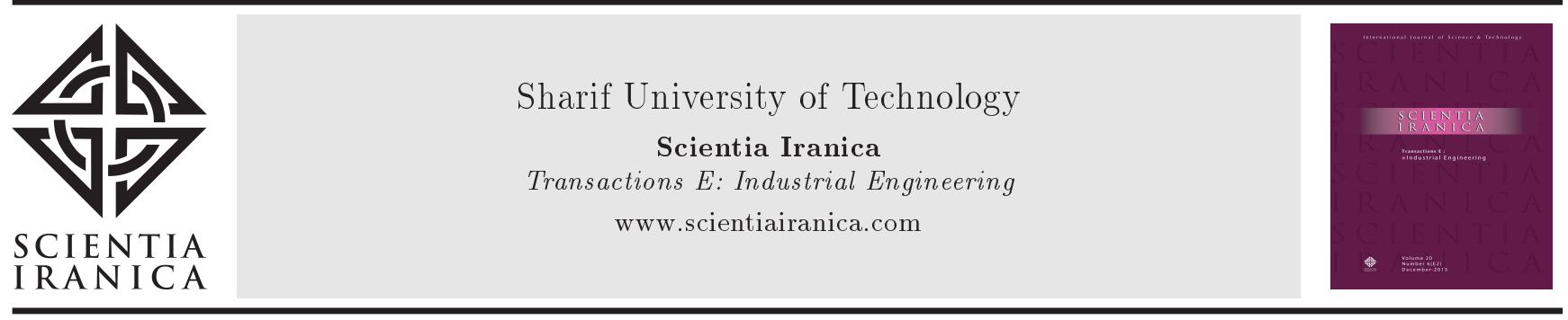

\title{
Optimizing reliability and cost of system for aggregate production planning in a supply chain
}

\author{
M. Ramyar ${ }^{\mathrm{a}}$, E. Mehdizadeh ${ }^{\mathrm{b}, *}$ and S.M. Hadji Molana ${ }^{\mathrm{a}}$ \\ a. Department of Industrial Engineering, College of Engineering, Tehran Science and Research Branch, Islamic Azad University, \\ Tehran, Iran. \\ b. Faculty of Industrial and Mechanical Engineering, Qazvin Branch, Islamic Azad University, Qazvin, Iran.
}

Received 25 January 2016; received in revised form 9 September 2016; accepted 3 October 2016

\author{
KEYWORDS \\ Aggregate production \\ planning; \\ Supply chain \\ management; \\ Reliability; \\ Multi-objective \\ harmony; \\ NSGA-II \& NRGA.
}

\begin{abstract}
In this paper, the researchers present a multi-objective model for multiproduct, multi-site aggregate production planning model in a supply chain. The goals are to minimize the total cost of the supply chain, including inventory costs, manufacturing costs, work force costs, hiring and firing costs, and also to maximize the minimum of suppliers' reliability by considering probabilistic lead times to simultaneously improve the system performance. Since the problem is NP-Hard, a Pareto-based multi-objective harmony search algorithm is proposed. To demonstrate the performance of the presented algorithm, a Non-dominated Sorting Genetic Algorithm (NSGA-II) and a Non-dominated Ranking Genetic Algorithm (NRGA) are applied. The results demonstrate the robustness of the proposed algorithm to probe the Pareto solutions.
\end{abstract}

2017 Sharif University of Technology. All rights reserved.

\section{Introduction}

A supply chain is a set of different parties, including suppliers, manufacturers, people, distribution centers, transportation channels, etc. in which each firm has a specific role in transforming raw materials to end products with regard to costumers' demand. In recent years, improvement in globalization, competition, integration, etc. has channelized firms to concentrate on the entire members involved in the supply chain, in addition to their individual production plans. Connecting all members of a supply chain together and providing production planning based on the relationships

*. Corresponding author. Tel/Fax: +982833670051 E-mail addresses: m.ramyar@srbiau.ac.ir (M. Ramyar); emehdi@qiau.ac.ir (E. Mehdizadeh); molana@srbiau.ac.ir (S.M. Hadji Molana)

doi: $10.24200 /$ sci.2017.4398 between the firms is one of the most important issues which can be conducted by Supply Chain Management (SCM). In other words, SCM should be able to plan all the activities involved in producing a product from suppliers to costumers in a supply chain. Inappropriate management of a supply chain leads to the bankruptcy of the members and failure in global competitions. One of the medium-range planning in the SCM, which includes a time horizon from 3 to 18 months, is Aggregate Production Planning (APP) in which aggregated products are considered instead of individual products. APP, as a technical level planning, attempts to determine the optimal quantity of production, inventory level, workforce, etc. in each period with regard to some constraints to satisfy the uncertain demand of all products [1]. The result of APP can be used as a base for other plans such as Capacity Requirements Planning (CRP), Master Production Schedule (MPS), and Material Requirements Planning (MRP) [2]. In a systematic view of APP, one can introduce capacity 


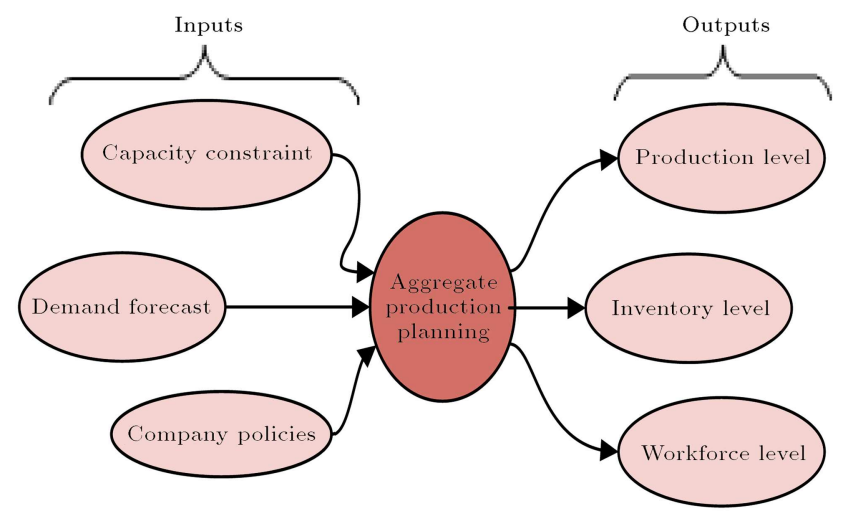

Figure 1. Inputs and outputs of APP process.

constraints, demands, and firm's policies and strategies as inputs of APP and determine the production levels, inventory levels, workforce levels, subcontracting, etc. as outputs of the system depicted in Figure 1.

Based on a number of the objective function, considered in the models, the APP models can be classified into two following categories: single-objective function problems and multi-objective function problems. A common objective function in the APP models is to minimize the total cost of the system. In addition, maximization of service level, minimization of changing of work force level, and minimization of the risk are other objective functions which can be considered.

Over the last decades, numerous single-objective APP models have been studied in the research studies. Various models have been developed to solve the APP problem since Holt et al. [3] presented HMMS (Holt, Modigliani, Muth and Simon) rule. Bergstrom and Smith [4] generalized the HMMS approach for multiproduct system. Oh and Karimi [5] developed a multiproduct supply chain planning model with a drawback. Guillen et al. [6] discussed a mixed-integer linear programming model for tactical planning of multiproduct supply chains.

All the above mentioned research studies discussed a single-objective APP model which tried to minimize the total cost, while the other objective functions can be considered in APP models. In other words, in the practical APP model, conflicting objective functions can be considered [7]. Wang and Liang [8] proposed a multi-objective APP model including minimizing the total costs, carrying and backordering costs, and changing workforce level in a fuzzy environment. Leung and Chan [9] proposed a multi-objective APP model which attempted to maximize profit, minimize repairing costs, and maximize machine utilization regarding different operational constraints. Baykasoglu and Gocken [10] used a direct solution method based on ranking methods of fuzzy numbers and Tabu search to solve fuzzy multi-objective aggregate production planning problem. Mirzapour Al-e-Hashem et al. [1] proposed a multi-objective mixed integer nonlinear programming model to deal with APP considering two conflicting objectives simultaneously as well as the uncertain nature of the supply chain. Mirzapour Al-eHashem et al. [11] introduced a multi-objective model, including minimizing the total cost, maximizing the service level, and maximizing workers' productivity, to deal with a multi-period, multi-product and multisite aggregate production planning problem under uncertainty. Sadeghi et al. [12] considered minimizing the total costs, carrying and backordering costs, and rate of changes in workforce level simultaneously by a multi-objective model for aggregate planning and used a goal programming approach to solve the proposed model. Rodger [13] used real-world data to determine the structure of a Bayesian network. In this research, stochastic simulation based on Markov blankets was used to determine the distribution of backorders and customer wait time in supply chains. Fuzzy logic was employed to produce a funnel diagram, demonstrating that the Acquisition Advice Code, Acquisition Method Suffix Code, Acquisition Method Code, and Controlled Inventory Item Code backorder performance metric of a trigger group dimension might change dramatically with variations in ALT, PLT, unit price, quantity ordered, and stock. Rodger et al. [14] reported on the results of fuzzy induced linguistic ordered weighted averaging for group decision support evaluation of backorder risk triggers to ensure that equipment is available and fully operational when needed. Risk factors were identified, the impact importance and probability metric performance ratings were determined via induced linguistic ordered weighted averaging, and a risk mitigation strategy was used to identify and predict Supply Chain Backorder Risk Triggers (SCBORT). Finally, they presented supply chain risk as a probability/impact matrix. Ramanathan [15] studied several supply chain management initiatives such as vendor-managed inventory, continuous replenishment, and Collaborative Planning Forecasting and Replenishment (CPFR) that had been previously proposed in the literature to improve the performance of supply chains. In this research, collaborative performance measurement acts as a testing tool to identify a helping environment to collaborate by pinpointing areas requiring improvements before initializing collaboration. Gholamian et al. [16] proposed a fuzzy multi-objective mixed-integer nonlinear programming (FMOMINLP) to address a comprehensive multi-site, multi-period and multi-product Aggregate Production Planning (APP) problem under uncertainty. They developed a fuzzy programming method to solve the presented model. Finally, the efficiency of the model was investigated by a real industry SC case study. Pasandideh et al. [17] proposed a bi-objective optimization of a multi-product, multi-period three-echelon supply-chain-network problem. To bring the problem 
closer to reality, the majority of the parameters in this network were considered stochastic. The problem was first formulated into the framework of a single-objective stochastic mixed integer linear programming model. Then, it was reformulated into a bi-objective deterministic mixed-integer nonlinear programming model. To solve the complicated problem, a Non-dominated Sorting Genetic Algorithm (NSGA-II) was utilized and Non-dominated Ranking Genetic Algorithm (NRGA) was used to validate the results obtained. Pasandideh et al. [18] investigated a bi-objective optimization of a multi-product multi-period three-echelon supply chain network consisting of manufacturing plants, Distribution Centers (DCs) with uncertain services for each one and customer nodes. The two objectives were the minimization of the total cost, while minimization of the average number of products dispatched to customers was followed by considering reliability indices assumed for the distribution centers. Rooeinfar et al. [19] proposed a new Supply Chain Network, and two novel hybrid algorithms were developed to solve the model. Each hybrid algorithm integrates the simulation technique with two metaheuristic algorithms, including the Genetic Algorithm (GA) and the Simulated Annealing Algorithm (SAA), namely HSIM-META. Computational results show that the proposed HSIM-META has suitable accuracy and speed for use in real-world applications. Entezaminia et al. [20] proposed a multiobjective, multi-period, multi-product and multi-site Aggregate Production Planning (APP) model in a green supply chain considering a Reverse Logistic (RL) network. In this model, minimizing the total losses and maximizing total environmental scores of products were the objective functions. They demonstrated the trade-off between the conflicting objective functions by a set of Pareto-optimal solutions as generated by the LP-metrics method.

It is obvious that in a chain with various suppliers, producing the raw material for manufacturers can be done in different ways. But, delivery time of the suppliers is not precise, and it is possible that delays occur in shipment of materials from suppliers to manufacturers. Hence, considering probabilistic lead time is more realistic. This lead time can be a measure for defining the reliability of suppliers, and consideration of their reliability can influence manufacturers' production. In other words, the selection of suppliers that maximizes the reliability of the whole system can be considered as another objective function in this paper.

Based on the complexity of the APP problems and the proposed problem associated with non-linear mixed integer programming models, using the exact or hardcomputing methods will be time-consuming, especially when the problem size increases [21]. This is proof of why we propose a meta-heuristic algorithm method to solve the proposed problem. Among multi-objective algorithms, a widely used Pareto-based algorithm is an extended version of a Genetic Algorithm (GA) for multi-objective problems, called Non-dominated Sorting Genetic Algorithm (NSGA-II) proposed by Deb et al. [22]. This algorithm can be used in different scopes of operational management. Harmony Search Algorithm (HSA), as a music-inspired algorithm, is simple in concept and has just a few parameters. It is easy to be implemented and has been successfully applied to different problems including the mechanical structure design [23], pipe network optimization [24], and inventory models [25].

In this paper, a multi-objective model considering a multi-period, multi-product, and multi-site aggregate production planning problem is developed. The first objective function is minimizing the sum of the total cost in the supply chain, and the second one, considered as a contribution, includes improving the performance of the system through maximizing the minimum suppliers' reliability by considering probabilistic lead times not discussed in the literature of multi-objective APP models. With regard to the complexity of the proposed APP model, we present a Multi-Objective Harmony Search Algorithm (MOHSA) and compare its results with those of the Non-dominated Sorting Genetic Algorithm (NSGA-II) and Non-dominated Ranking Genetic Algorithm (NRGA) as the best-developed Pareto-based approaches in the literature.

The rest of this paper is organized as follows: A mathematical formulation of the proposed multiobjective APP problem is presented in Section 2. The solution procedure and parameter tuning are proposed in Sections 3 and 4, respectively. Section 5 provides the result analysis and comparisons. Finally, conclusion and suggestion for future research are presented in Section 6.

\section{Problem formulation}

The proposed APP problem in a supply chain can be described as follows: there are $S$ suppliers, $J$ manufacturers, and $C$ customers, as shown in Figure 2. Each supplier can produce several items with regard to its capacity constraint and transport them to the manufacturers. Each manufacturer is able to produce several products according to the needed raw materials provided by suppliers and subcontracting is allowed for the manufacturer. There is a restricted available time for manufacturing. For each supplier and manufacturer, the production cost of each item can be different. The warehouse capacity of manufacturers for raw materials and end products is limited. The produced end products are transported to costumers' zones regarding their demands. Based on geographical distribution of supply chain's members, including suppliers, manufacturers, and costumers in an area, the 


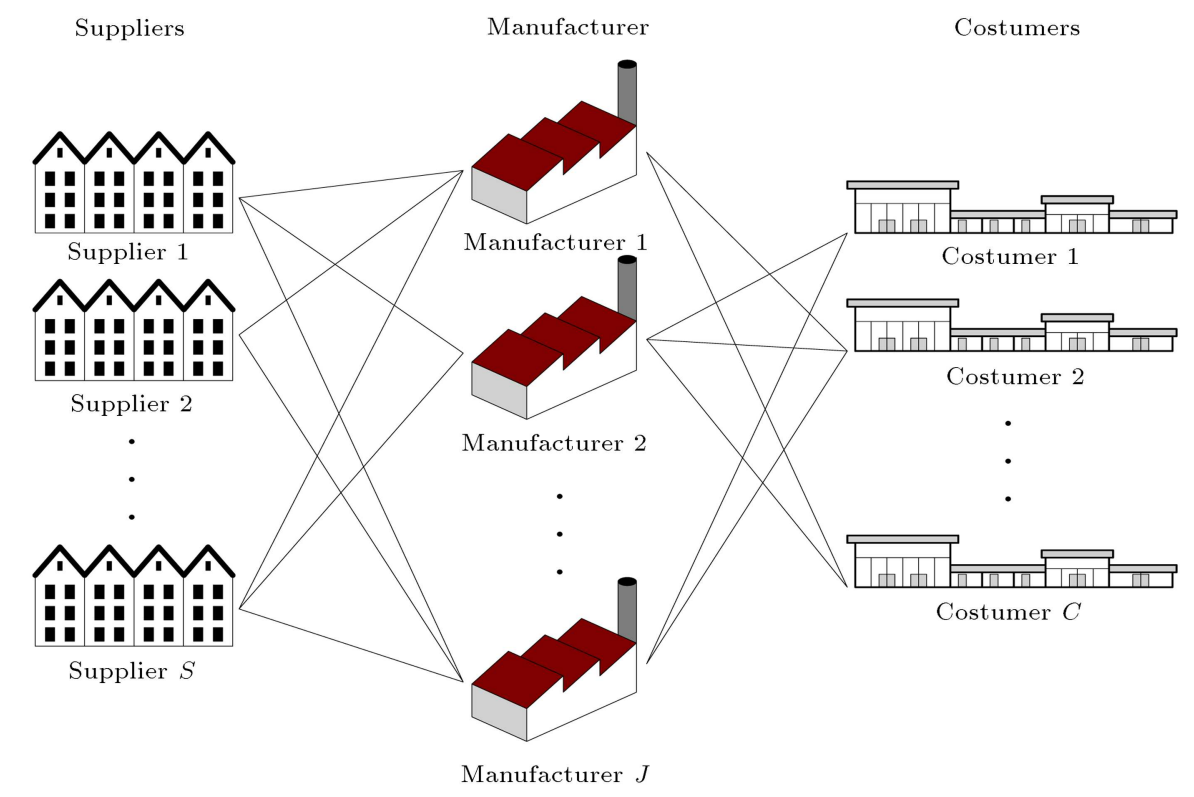

Figure 2. Supply chain configuration.

transportation time between them can vary. Shortage can occur for each product. The probabilistic lead time for transporting raw materials from suppliers to manufacturers is considered, and the reliability of suppliers in delivering materials can be computed based on this definition. In other words, a supplier is reliable if he can transport the needed raw materials to a manufacturer in a predefined duration time.

This paper models the APP problem as a biobjective programming with the following objective functions:

1. Minimizing the total cost of supply chain;

2. Maximizing performance level by maximizing reliability in supplier selection process.

\subsection{Notations}

The parameters in this model are as follows:

$D_{i c t}: \quad$ Demand of product $i(1,2, \ldots, I)$ in demand point $c(1,2, \ldots, C)$ in period $t$ $(1,2, \ldots, T)$

$C_{q j}$ : $\quad$ Production cost per hour in regular time $(q=1)$, overtime $(q=2)$, and subcontracting $(q=3)$ at factory $j$ $(1,2, \ldots, J)$

$L_{j t}: \quad$ Manpower cost of labors at factory $j$ in period $t$

$a_{i j}: \quad \quad \quad \quad$ Production time of product $i$ at factory

$F_{j t}: \quad$ Firing cost of workers at factory $j$ in period $t$

$H_{j t}$ : $\quad$ Hiring cost of workers at factory $j$ in period $t$
$I_{1 m j t}$ : Inventory holding cost for raw material $m(1,2, \ldots, M)$ at factory $j$ in period $t$

$I_{2 i j t}$ : Inventory holding cost for finished product $i$ at factory $j$ in period $t$

$I_{3 i c t}$ : $\quad$ Inventory holding cost for finished product $i$ in costumer's zone $c$ in period $t$

$T_{1 \text { sjt }}$ : Transportation cost for supplier $s$ $(1,2, \ldots, S)$ to factory $j$ in period $t$

$T_{2 i c t}$ : $\quad$ Transportation cost from factory $j$ to demand point $c$ in period $t$

$C r_{s m t}$ : Cost of raw material $m$ provided by supplier $s$ in period $t$

$\gamma_{i m}: \quad \quad$ Number of units of raw material $m$ required for each unit of product $i$

$\alpha_{t}$ : $\quad$ Fraction of the workforce variation allowed in period $t$

$\nu: \quad$ Productivity of labors $(0 \leq \nu \leq 1)$

$T I_{q j t}: \quad$ Available regular time $(q=1)$, overtime $(q=2)$, and capacity of subcontracting $(q=3)$ in terms of time unit at factory $j$ in period $t$

$P_{1 j}$ : $\quad$ Raw material storage capacity at factory $j$

$P_{2 j}$ : $\quad$ End product storage capacity at factory $j$

$P_{3 c}$ : $\quad$ End product storage capacity in customer's zone $c$

$P_{4 s m t}: \quad$ Maximum number of raw material $m$ supplier $s$ could be provided in period $t$ 
$L T_{s j}: \quad$ Probabilistic lead time for shipping raw material from supplier $s$ to factory

$$
j
$$

$\varphi_{L T}: \quad$ Maximum acceptable lead time of supplier for being reliable

$L T_{j c}$ : $\quad$ Lead time required for shipping end products from factory $j$ to demand point $c$

$\pi_{i c t}: \quad \quad \quad \quad$ Shortage cost of product $i$ in customer's zone $c$ in period $t$

$T C$ : $\quad$ Total Cost of supply chai

$r_{s j}=P\left(L T_{s j}<\varphi_{L T}\right)$ : Reliability of supplier $s$ for providing required raw materials of factory $j$

\section{Decision variables}

$X_{i j q t} \quad$ Number of product $i$ produced at factory $j$ using method $q$ in period $t$

$X L_{j t} \quad$ Number of workers at factory $j$ in period $t$

$X F_{j t} \quad$ Number of workers at factory $j$ fired in period $t$

$X H_{j t} \quad$ Number of workers at factory $j$ hired in period $t$

$X M_{m j t} \quad$ Inventory level of raw material $m$ at factory $j$ at the end of period $t$

$X P_{i j t} \quad$ Inventory level of end product $i$ at factory $j$ in period $t$

$X I_{i c t} \quad$ Inventory level of end product $i$ in customer's zone $c$ in period $t$

$X S_{s m j t} \quad$ Number of units of raw material $m$ shipped from supplier $s$ to factory $j$

$Y S_{i j c t} \quad$ Number of units of end product $i$ provided by factory $j$ for demand point $c$ in period $t$

$z_{s j t} \quad$ One if supplier $s$ provides at least one of the raw materials for factory $j$ in period $t ; 0$ otherwise

$B_{i c t} \quad$ Shortage of product $i$ in demand point $c$ in period $t$

$O \quad$ One if the total cost of the supply chain is violated from a pre-specified value $(\Omega) ; 0$ otherwise.

\subsection{Multi-objective APP model}

The multi-objective APP model can be stated as follows:

$$
\begin{aligned}
& \operatorname{Min} Z_{1}=T C=\sum_{i, j, q, t} a_{i j} C_{q j} X_{i j q t} \\
& +\sum_{s, m, j, t} C r_{s m t} X S_{s m j t}+\sum_{j, t} L_{j t} X L_{j t}
\end{aligned}
$$

$$
\begin{aligned}
& +\sum_{j, t} F_{j t} X F_{j t}+\sum_{j, t} H_{j t} X H_{j t} \\
& +\sum_{m, j, t} I_{1_{m j t}} X M_{m j t}+\sum_{i, j, t} I_{2_{i j t}} X P_{i j t} \\
& +\sum_{i, c, t} I_{3_{i c t}} X I_{i c t}+\sum_{s, m, j, t} T_{1_{s j t}} X S_{s m j t} \\
& +\sum_{i, j, c, t} T_{2_{i c t}} Y S_{i j c t}+\sum_{i, c, t} \pi_{i c t} B_{i c t},
\end{aligned}
$$

$X P_{i j t}=X P_{i j(t-1)}+\sum_{q} X_{i j q t}-\sum_{c} Y S_{i j c t} \quad \forall i, j, t$,

$$
\left.X M_{m j t}=X M_{m j(t-1)}+\sum_{s} X S_{s m j\left(t-\mu_{L T} j\right.}\right)
$$$$
-\sum_{q, i} x_{i j q_{t}} \cdot \gamma_{i m} \quad \forall m, j, t
$$

$$
X L_{j t}=X L_{j(t-1)}+X H_{j t}-X F_{j t} \quad \forall j, t
$$

$X I_{i c t}=X I_{i c(t-1)}+\sum_{j} Y S_{i j c\left(t-\mu_{L T} T_{s j}\right)}-D_{i c t}$

$$
-B_{i c(t-1)} \quad \forall i, c, t
$$

$X L_{j t} \nu\left(T I_{1_{j t}}+T I_{2_{j t}}\right) \geq \sum_{i, q \in\{1,2\}} x_{i j q t} . a_{i j} \quad \forall j, t$

$\sum_{i} x_{i j 3 t} \cdot a_{i j} \leq T I_{3 j t} \quad \forall j, t$

$\sum_{m} X M_{m j t} \leq P_{1 j} \quad \forall j, t$,

$\sum_{i} X P_{i j t} \leq P_{2 j} \quad \forall j, t$

$\sum_{m} X I_{i c t} \leq P_{3 c} \quad \forall c, t$

$\left(X F_{j t}+X H_{j t}\right) \leq \alpha_{(t-1)}\left(X L_{j(t-1)}\right) \quad \forall j, t$,

$\sum_{j} X S_{s m j t} \leq P_{4 s m t} q q u a d \forall s, m, t$,

$X S_{s m j t} \leq M . z_{s j t} \quad \forall m, s, j, t$,

$z_{s j t} \in\{0,1\}$,

$X F_{j t}, X H_{j t}, X L_{j t} \geq 0$ and integer $\forall j, t$, 


$$
\begin{gathered}
X_{i j q t}, X S_{j s m t}, X M_{m j t}, X P_{i j t}, Y S_{i j c t}, B_{i c t}, X F_{j t}, \\
X H_{j t}, X L_{j t} \geq 0 \quad \forall i, j, c, s, m, t .
\end{gathered}
$$

In this model, Eq. (1) denotes the first objective function aiming to minimize the total cost of the supply chain including production cost of manufacturers and suppliers, workforce hiring and firing costs, inventory costs, transportation costs, and shortage costs. The second objective function (Eq. (2)) attemp ts to improve performance level through maximizing the minimum of suppliers' reliability. In this function, it should be considered that the minimization operator is defined for $\left\{s, j \mid z_{s j t}=1\right\}$. By this consideration, the system tries to confirm a balance in supplier selection problems. Eqs. (3) and (4) are balance constraints for inventory of end product and raw material, respectively. Eq. (5) ensures the workforce level balance. An inventory balance equation of demand point $c$ is considered in Eq. (6). Eq. (7) guarantees that for each manufacturer, the sum of regular time and overtime with regard to productivity of workforce limits the available production time. Eq. (8) is a subcontracting constraint. Eqs. (9) to (11) limit the raw material, end product inventory levels of manufacturers, and costumer zones' to their related inventory storage capacities, respectively. Eq. (12) limits the change in workforce level by the proportion of workers in the previous period. Eq. (13) restricts the amount of shipments from supplier $s$ by the supplier capacity. Eq. (14) ensures that if supplier $s$ provides at least one of the raw materials for factory $j$ in period $t$, its related binary variable $\left(z_{s j t}\right)$ must be one. Eqs. (15)-(17) denote variable types.

\section{The solution procedures}

Pareto-based approaches have been widely used in research studies, especially in order to solve complicated models. Based on NP-hardness of aggregate production planning, we present a multi-objective Pareto-based meta-heuristic algorithm called MOHSA and compare it with two based-developed ones in the literature, NSGA-II and NRGA, which are described in this section.

A multi-objective problem consists of some conflicting objectives $f(\vec{x})=\left[f_{1}(\vec{x}), \ldots, f_{m}(\vec{x})\right]$ with regard to some constraints $g_{i}(\vec{x}) \leq 0, i=1,2, \ldots, c, \vec{x} \in X$ where $\vec{x}$ denotes $n$-dimensional vectors and $X$ is the feasible region. For a minimization model, we say that solution $\vec{a}$ dominates solution $\vec{b}(\vec{a}, \vec{b} \in X)$ if:

1. $f_{i}(\vec{a}) \leq f_{i}(\vec{b}), \forall i=1,2, \ldots, m$ and;

2. $\exists i \in\{1,2, \ldots, m\}: f_{i}(\vec{a})<f_{i}(\vec{b})$.

There are some solutions that cannot dominate each other. The set of these solutions is called Pareto solutions set or Pareto front. Pareto-based algorithms try to find the optimal front during the evolution process, which is achieved in the last iteration of algorithm. This front is expected to have the most convergence and the highest diversity [22].

\subsection{The MOHSA}

In HSA, the objective function is interpreted as harmony, and aesthetic estimation of the player helps $\mathrm{him} /$ her to find good state of the harmony. Indeed, in this algorithm, the qualitative improvisation process is turned into quantitative optimization process. Therefore, in this paper, multi-objective version of HSA is developed and presented to the literature of APP. The details of MOHSA are described in the following subsections.

\subsubsection{Solution representation}

To code the solutions, we presented a bi-part solution representation structure. A $1 \times S$ random vector specifies the priority of suppliers for transporting materials into the manufacturer, and a $1 \times J$ random vector specifies the priority of manufacturers for producing the products. Figure 3 schematically represents an example of this structure. In this structure, each gene of vectors is a random number between zero and one. Besides, customers' demands will never exceed the capacity limitations throughout the supply chain. In this figure, $S=4$; so, the random numbers are generated as $1 \times 4$ vector; their positions are kept, and then sorted in an ascending order. Based on our capacity, two of the first genes are selected. The positions of these numbers are selected as suppliers (suppliers numbers 3 and 1 are selected based on the corresponding capacity). Moreover, the continuous decision variables, including $X_{i j q t}, X S_{j s m t}, X M_{m j t}, X P_{i j t}, Y S_{i j c t}$, $B_{i c t}, X F_{j t}, X H_{j t}$, and $X L_{j t}$, are encoded based on upper bounds and are randomly generated between zero and its upper bound.

To prevent violation of constraints, a penalty function approach method is applied to penalize them [26]. Penalty values are considered for all of the two-objective functions through an additive function.

\subsubsection{Improvising process}

In an improvisation of the process of a musician, when a musician improvises with an instrument, he or she faces three possible options of:

(I) Playing from his/her memory (with probability $\left.P_{\mathrm{HMCR}}\right)$;

\begin{tabular}{l|r|r|r|r|}
\cline { 2 - 5 } Generated vector & 0.39 & 0.90 & 0.23 & 0.45 \\
\cline { 2 - 5 } Sorted vector & $\begin{array}{r}0.23 \\
(3)\end{array}$ & $\begin{array}{c}0.39 \\
(1)\end{array}$ & $\begin{array}{c}0.45 \\
(4)\end{array}$ & $\begin{array}{r}0.90 \\
(2)\end{array}$ \\
\hline
\end{tabular}

Figure 3. An instance of DCs encoding. 
(II) Adjusting the pitches slightly (with probability $\left.P_{p a}\right)$;

(III) Composing randomly (with probability $P_{\text {rand }}$ ).

These options are formalized into three quantitative operators in HSA called harmony memory, pitch adjusting, and randomization [27]. Therefore, the improvising process of the HSA is the combination of these three operators. Accordingly, the main steps of the HSA are explained in the next subsections. To apply the improvising process in different iterations, a random solution is selected first, and then one/two operator(s) of the HSA (based on their probabilities) is/are used to improvise the selected solution. After improvising a new solution, the HSM is updated by replacing the worse solution with the new solution. Interested readers should refer to Geem et al. [24], Geem [28], and Rahmati et al. [29] for additional information. Figure 4 presents a schematic view of the relationship between different HSA probabilities.

Besides, to minimize the impact of using different operators on the performance comparison process of the algorithms, operators are designed identically. To do so, the pitch adjusting operator of MOHSA is designed similar to the mutation operator of the GA as a swap strategy $[27,29]$. We also represent the Pseudocode of HSA as well in Figure 5.

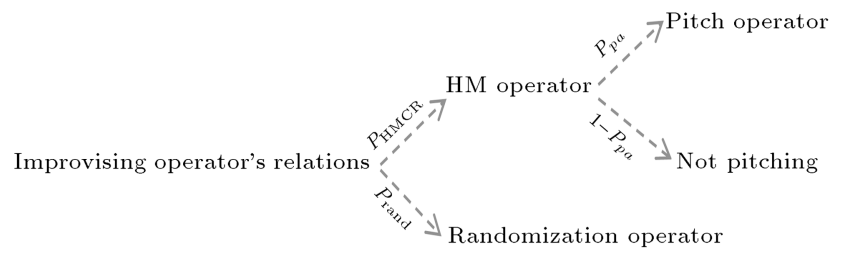

Figure 4. The relationship among different probabilities of HAS.

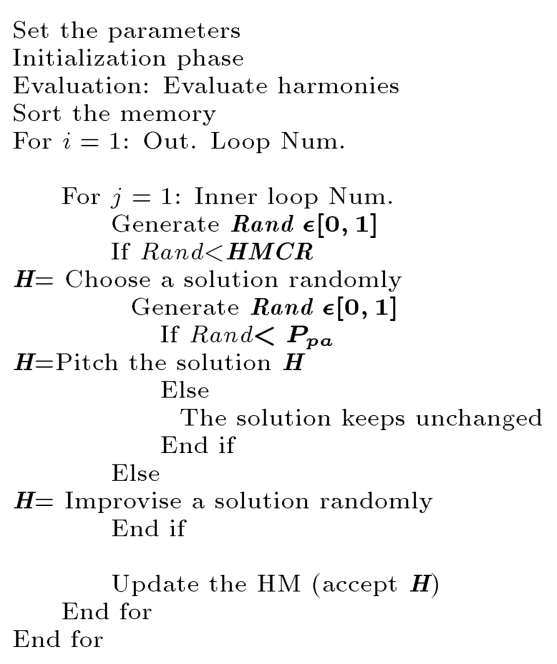

Figure 5. HSA Pseudo-code [29].

\subsubsection{Multi-objective operators of the MOHS}

While the objective function value was used to rank the solutions in a single-objective algorithm, the domination concept was utilized for ranking Pareto-based multi-objective algorithms. In the NSGA-II algorithm, as proposed by Deb et al. [22], the Fast Non-Dominated Sorting (FNDS) operator was employed for inserting the dominance concept by searching the first goal called convergence. Smaller values of FNDS indicate better ranks. To search the second goal named diversity, another operator named Crowing Distance (CD) was considered in NSGA-II to estimate the density of similar rank solutions placed surrounding a particular solution. Larger values of $\mathrm{CD}$ show better solutions lying in a less crowded area. Then, a binary tournament selection is performed according to the above two operators, in which if solutions are from different ranks, the one with a smaller rank is selected. Otherwise, the one with the more value of $\mathrm{CD}$ is selected.

The process is initiated by initializing the initial population of harmony vectors, $P_{t}$. Then, the new operators, including HM, migration, and mutation, are implemented on $P_{t}$ to create a new population, $Q_{t}$. The combination of $P_{t}$ and $Q_{t}$ creates $R_{t}$ for keeping elitism in the algorithm. In this step, vectors of $R_{t}$ are sorted in several fronts based on FNDS and CD [22]. Using the proposed selection method, population of the next iteration, $P_{t+1}$, is chosen to have a predetermined size. Figure 6 demonstrates the evolution process of the proposed MOHS, schematically.

To demonstrate performance of the proposed MOHSA, two well-developed Pareto-based multiobjective evolutionary algorithms, called NSGA-II and NRGA, are applied, described in the following subsection.

\subsection{The NSGA-II and NRGA}

Non-dominated Sorting Genetic Algorithm (NSGA) is one of the most popular evolutionary algorithms, used to solve multi-objective problems. This non-dominated based meta-heuristic algorithm, which is an extension of the Genetic Algorithm (GA), was proposed by Srinivas and Deb [30]. The main criticisms of the NSGA, such as lack of elitism, the need for specifying the sharing parameter, and high computational complexity of non-dominated sorting, lead to introducing an extension of NSGA, called NSGA-II, proposed by Deb et al. [22].

In this paper, we apply an NSGA-II approach to solve the proposed APP model and compare the results with those of the presented MOHSA approach. As another Pareto-based evolutionary algorithm, NRGA is another multi-objective evolutionary algorithm introduced by Al Jaddan et al. [31] to solve multi-objective optimization problems. The crossover and mutation operators of NSGA-II and NRGA are uniform crossover 


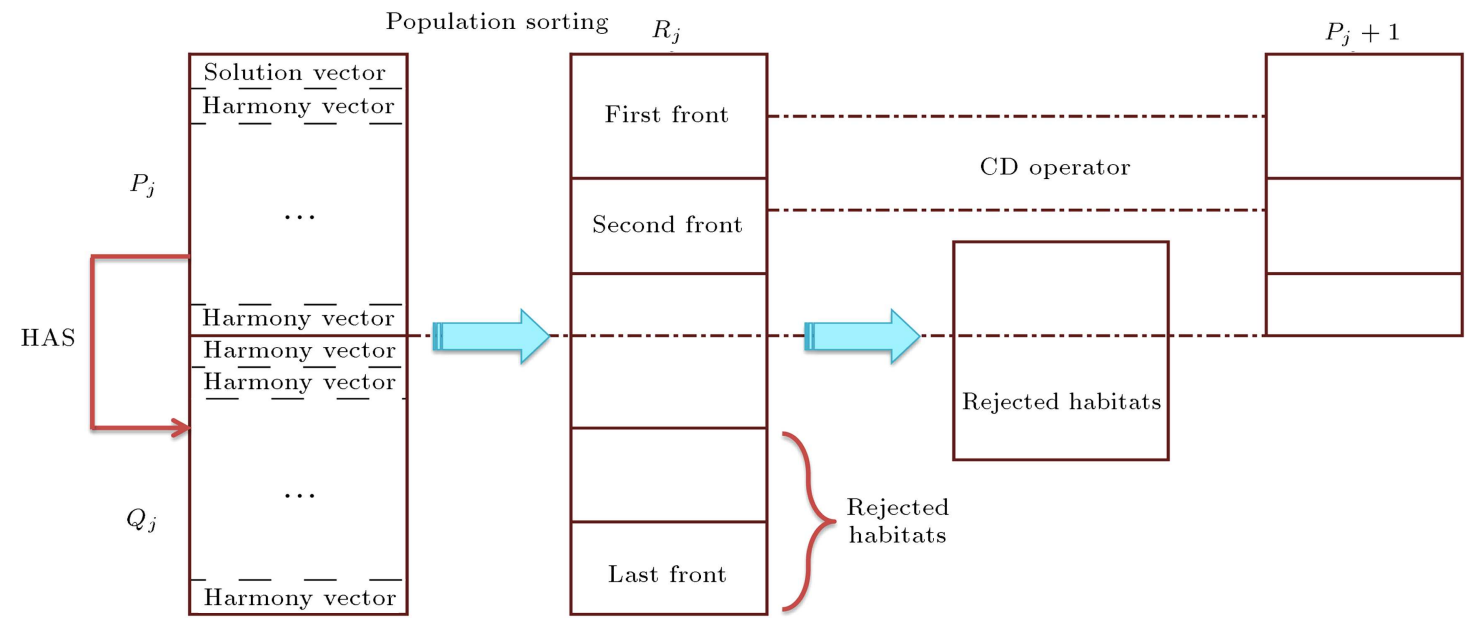

Figure 6. MOHSA evolution process.
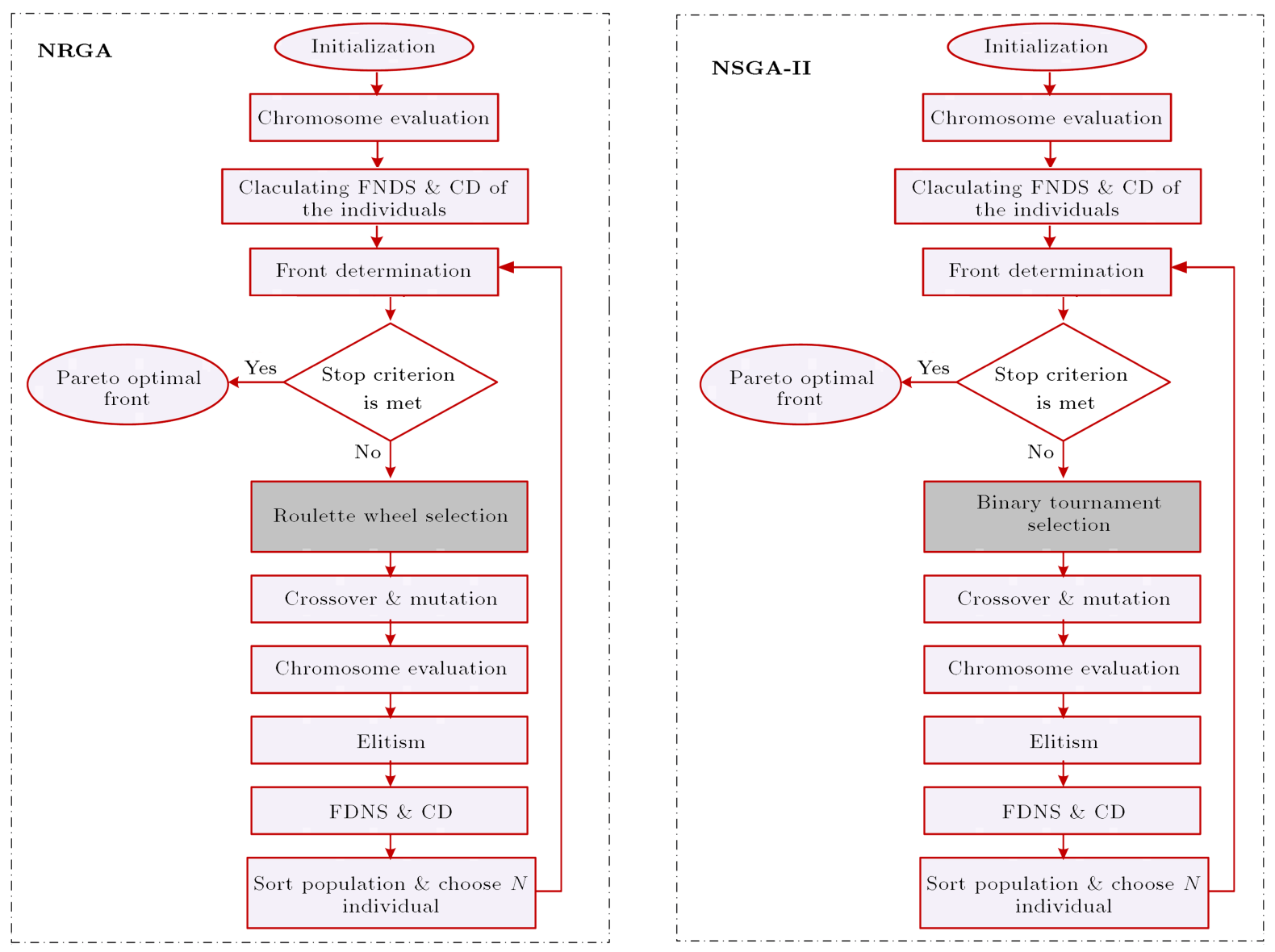

Figure 7. NSGA-II and NRGA flowcharts.

and swap operators, respectively [32]. Further, binary tournament selection and roulette wheel selection strategies methods are applied in NSGA-II and NRGA, respectively. The flowcharts of NSGA-II and NRGA are plotted in Figure 7 .

\section{Parameter tuning}

Since the quality of meta-heuristic algorithms largely depends on the parameters and operators, Experiments designs are used to set the parameters. Experiments designs is an organized method to determine the relationship between input and output processes. In this section, parameters and operators of MOHSA are determined. Due to the large number of parameters in HSA, finding a suitable composition of parameters that improves the performance of algorithms is favorable. Since there are many parameters, using complete 
factorial method is insufficient. To solve this problem, Taguchi method has been used. In this section, to set the parameters, several large-scale problems have been selected and are presented in Figures 8-10 by using major effect chart. In the cases where the number of agents and their levels is high, Taguchi method is more efficient than complete factorial method. For orthogonal array, L27 equaling 27 is much less than the number required for complete factorial method $[33,29]$. In order to tune the parameters, the Mean Ideal Distance (MID) is selected as the main response in Taguchi analysis.

According to the main effects plots of Figures 810 , the optimal value of the algorithm's parameters for problem no. 10 is reported in Table 1.

\section{Result analyses and comparisons}

This section provides the application of the proposed methodology and the performance comparisons of the three meta-heuristic algorithms. The developed algorithms are coded in MATLAB software (Version 7.10.0.499, R2010a) environment, and the experiments

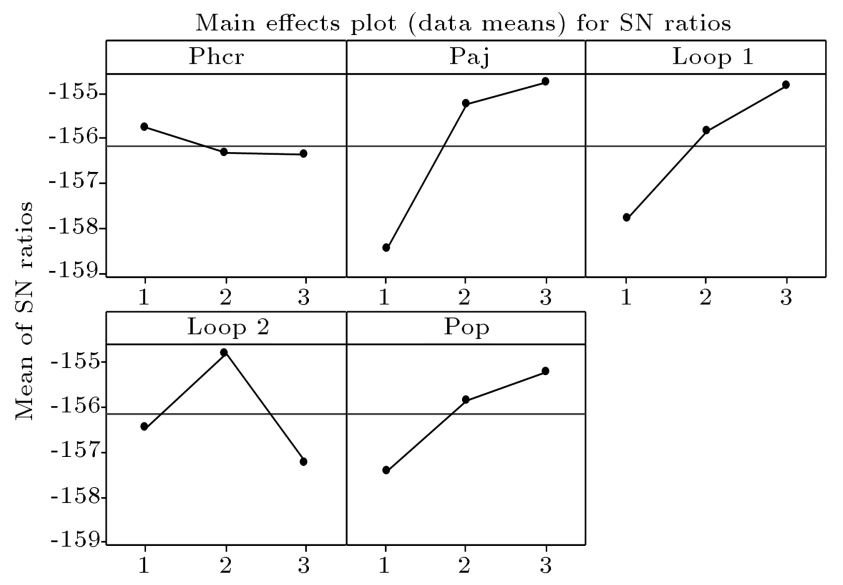

Signal-to-noise: Smaller is better

Figure 8. Setting the MOHSA parameters by Taguchi. are performed on a two $\mathrm{GHz}$ laptop with eight GB RAM to estimate the response functions.

To evaluate and compare the performances of the

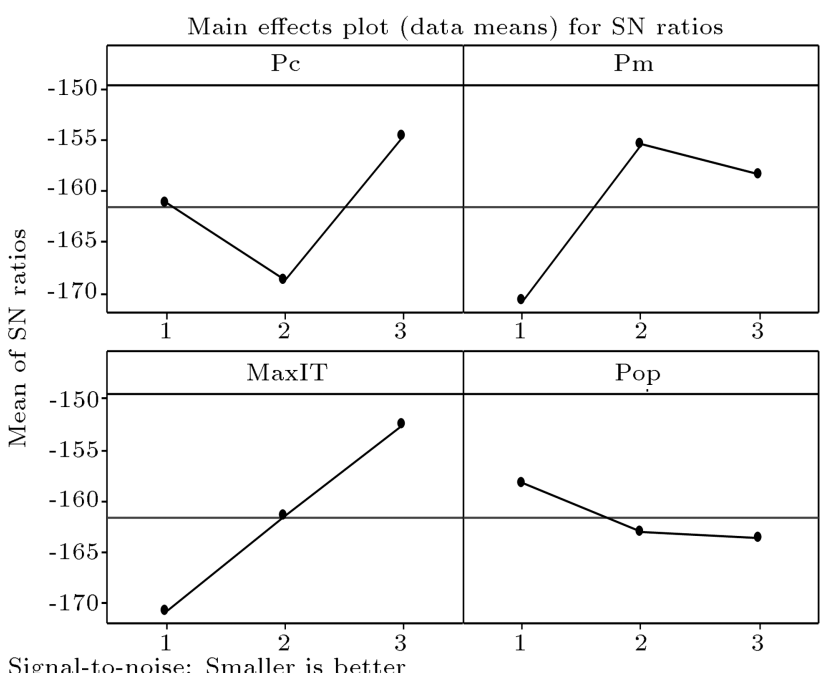

Signal-to-noise: Smaller is bette

Figure 9. Setting the NRGA parameters by Taguchi.

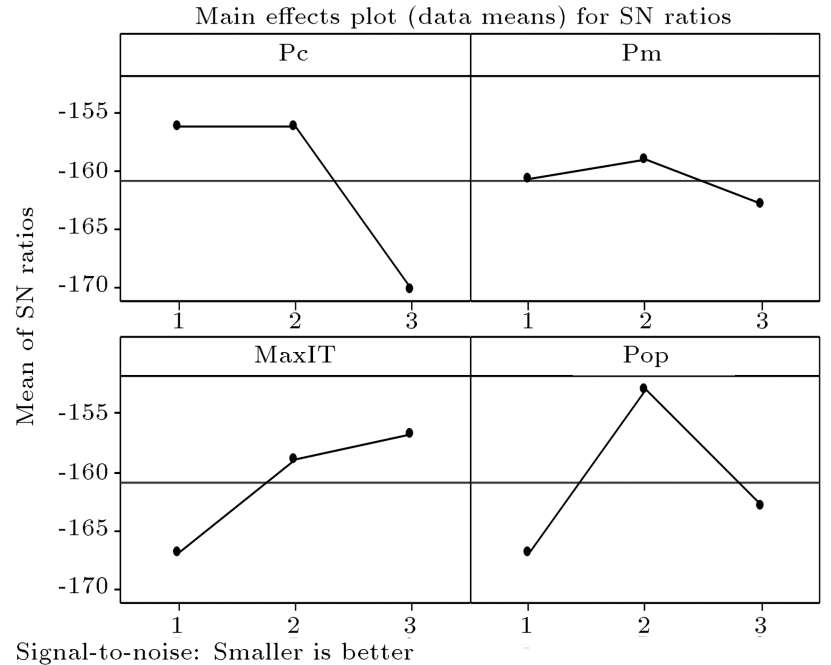

Figure 10. Setting the NSGA-II parameters by Taguch.

Table 1. Optimal parameters for the algorithms.

\begin{tabular}{clcc}
\hline Algorithms & Parameters & Leveling & Factor optimal \\
\hline \multirow{4}{*}{ MOHSA } & Population size (Pop) & $\{20,30,50\}$ & 50 \\
& Inner Loop (Loop1) & $\{20,30,40\}$ & 40 \\
& Outer Loop (Loop2) & $\{30,60,90\}$ & 60 \\
& Pitch adjusting operator (Paj) & $\{0.1,0.3,0.5\}$ & 0.5 \\
& Harmony memory operator (Phcr) & $\{0.7,0.8,0.9\}$ & 0.7 \\
& & & \\
& Population size (Pop) & $\{25,50,100\}$ & 25 \\
& Maximum of Iteration (MaxIT) & $\{100,200,300\}$ & 300 \\
& Probability of crossover (Pc) & $\{0.7,0.8,0.9\}$ & 0.9 \\
& Probability of mutation (Pm) & $\{0.1,0.25,0.4\}$ & 0.25 \\
& & & \\
& Population size (Pop) & $\{25,50,100\}$ & 50 \\
NSGA-II & Maximum of Iteration (MaxIT) & $\{100,200,300\}$ & 300 \\
& Probability of crossover (Pc) & $\{0.7,0.8,0.9\}$ & 0.8 \\
& Probability of mutation (Pm) & $\{0.1,0.25,0.4\}$ & 0.25 \\
\hline
\end{tabular}


Table 2. Generated test problem.

\begin{tabular}{ccccc}
\hline Problem no. & $\boldsymbol{I}$ & $\boldsymbol{C}$ & $\boldsymbol{T}$ & $\boldsymbol{J}$ \\
\hline $\mathbf{1}$ & 2 & 2 & 2 & 1 \\
$\mathbf{2}$ & 2 & 5 & 2 & 1 \\
$\mathbf{3}$ & 3 & 5 & 3 & 2 \\
$\mathbf{4}$ & 3 & 10 & 3 & 2 \\
$\mathbf{5}$ & 5 & 10 & 6 & 3 \\
$\mathbf{6}$ & 5 & 10 & 6 & 3 \\
$\mathbf{7}$ & 10 & 20 & 12 & 4 \\
$\mathbf{8}$ & 10 & 20 & 12 & 4 \\
$\mathbf{9}$ & 10 & 40 & 12 & 5 \\
$\mathbf{1 0}$ & 20 & 40 & 18 & 5 \\
$\mathbf{1 1}$ & 20 & 50 & 24 & 10 \\
$\mathbf{1 2}$ & 35 & 50 & 24 & 10 \\
\hline
\end{tabular}

Table 3. Input Parameters' values of the numerical examples.

\begin{tabular}{ll}
\hline \multicolumn{2}{c}{ Parameters and their values } \\
\hline$D_{i c t} \sim U(100,500)$ & $T_{2 i c t} \sim U(10,30)$ \\
$C_{q j} \sim U(10,40)$ & $C r_{s m t} \sim U(80,120)$ \\
$L_{j t} \sim U(1000,3000)$ & $\gamma_{i m} \sim U(3,9)$ \\
$a_{i j} \sim U(10,20)$ & $\alpha_{t} \sim U(0,1)$ \\
$F_{j t} \sim U(2000,4000)$ & $T I_{1, j t} \sim U(7,9)$ \\
$H_{j t} \sim U(6000,10000)$ & $T I_{2, j t} \sim U(0,4)$ \\
$I_{1 m j t} \sim U(100,200)$ & $P_{1 j} \sim U(1000,2000)$ \\
$I_{2 i j t} \sim U(150,250)$ & $P_{2 j} \sim U(500,1000)$ \\
$I_{3 i c t} \sim U(150,250)$ & $P_{3 c} \sim U(800,1400)$ \\
$\pi_{i c t}^{n} \sim U(100,400)$ & $P_{4 s m t} \sim U(1000,5000)$ \\
$L T_{s j}, L T_{j c} \sim$ Uniform $(0,4)$ & $\varphi_{L T}=1$ \\
$T_{1 s j t} \sim U(10,30)$ & \\
\hline
\end{tabular}

solution methodologies under different environments, the experiments are implemented on 12 problems, which are reported in Table 2. These problems are categorized based on the number of costumers $(I)$, the number of facilities $(J)$, and the maximum number of on-duty servers $(P)$. Moreover, the following information is also given in Table 3 .

Then, these instance problems are solved by three algorithms. Furthermore, to eliminate uncertainties of the solutions obtained, each problem is used three times under different random environments. Then, the averages of these three runs are treated as the ultimate responses. The objective function values of problems nos. 8 and 11 are reported in Tables 4 and 5 .

In order to evaluate the performances of the three multi-objective meta-heuristic algorithms, four metrics are used as Zitzler and Thiele [34]:

(I) Number of Pareto Solution (NOS);

(II) Mean Ideal Distance (MID);

(III) Spacing;

(IV) Diversity;

(V) Computational time.

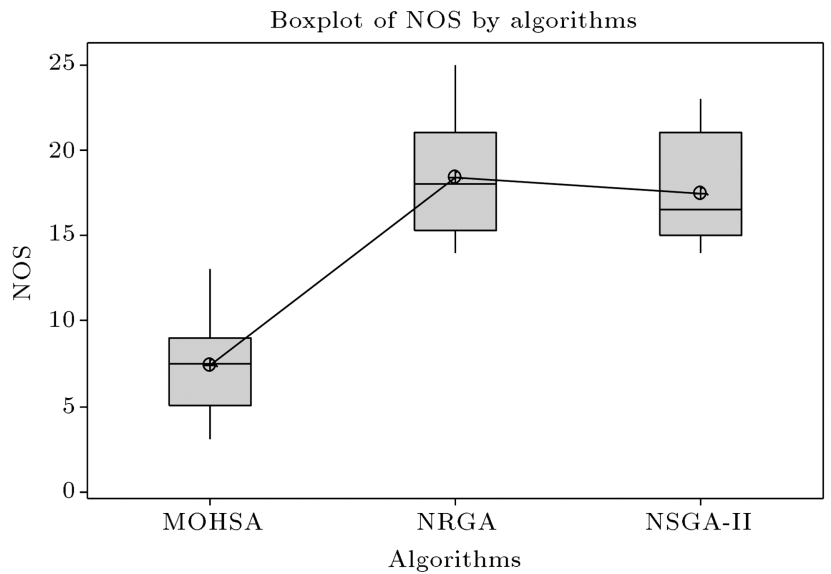

Figure 11. Box-plot comparisons of the algorithms in terms of NOS metric.

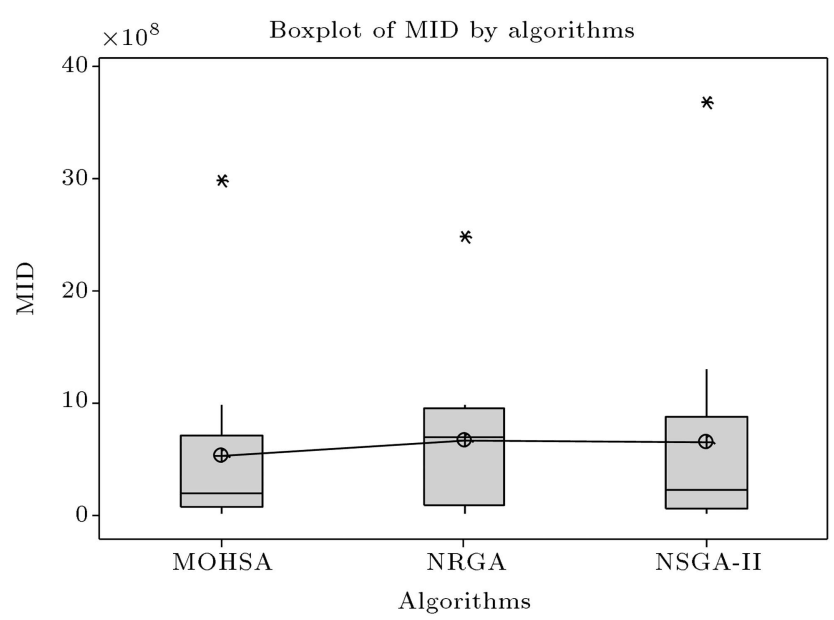

Figure 12. Box-plot comparisons of the algorithms in terms of MID metric.

The results of comparisons in terms of all multiobjective metrics for all algorithms are reported in Table 6. Moreover, the algorithms are compared based on the properties of their obtained solutions. For these cases, all metrics are also plotted and graphically compared in Figures 11-15.

We note that while bigger values are desired in terms of the diversity and NOS metrics, smaller values are better for spacing, MID, and CPU time. Thus, according to the analysis of variance outputs in Tables 7-11 and $p$-values, MOHSA shows better performance in terms of CPU Time. However, in terms of MID, Diversity, and Spacing metrics, the algorithms almost work in a similar way. This conclusion is confirmed at a $95 \%$ confidence level.

\section{Conclusion and future research}

A multi-objective model for multi-product, multi-site aggregate production planning model in a supply chain was developed in this paper. The goals were to 
Table 4. Pareto solutions of problem no. 8.

\begin{tabular}{|c|c|c|c|c|c|c|}
\hline \multirow{2}{*}{$\begin{array}{c}\text { Pareto solution } \\
\text { number }\end{array}$} & \multicolumn{2}{|c|}{ NSGA-II } & \multicolumn{2}{|c|}{ NRGA } & \multicolumn{2}{|c|}{ Proposed MOHSA } \\
\hline & Objective 1 & Objective 2 & Objective 1 & Objective 2 & Objective 1 & Objective 2 \\
\hline 1 & $6.53 \mathrm{E}+07$ & 0.5086 & $5.09 \mathrm{E}+07$ & 0.3450 & $1.39 \mathrm{E}+07$ & 0.3501 \\
\hline 2 & $8.01 \mathrm{E}+07$ & 0.6715 & $4.59 \mathrm{E}+07$ & 0.2567 & $5.27 \mathrm{E}+07$ & 0.6990 \\
\hline 3 & $3.50 \mathrm{E}+07$ & 0.1481 & $4.39 \mathrm{E}+07$ & 0.2244 & $9.19 \mathrm{E}+07$ & 0.9344 \\
\hline 4 & $7.61 \mathrm{E}+07$ & 0.6324 & $9.54 \mathrm{E}+07$ & 0.8702 & $8.02 \mathrm{E}+07$ & 0.8890 \\
\hline 5 & $9.84 \mathrm{E}+07$ & 0.8344 & $7.47 \mathrm{E}+07$ & 0.6397 & $6.65 \mathrm{E}+07$ & 0.8082 \\
\hline 6 & $5.60 \mathrm{E}+07$ & 0.4225 & $8.79 \mathrm{E}+07$ & 0.7854 & $6.01 \mathrm{E}+07$ & 0.7516 \\
\hline 7 & $9.35 \mathrm{E}+07$ & 0.8043 & $6.88 \mathrm{E}+07$ & 0.5773 & - & - \\
\hline 8 & $4.92 \mathrm{E}+07$ & 0.3671 & $7.78 \mathrm{E}+07$ & 0.6733 & - & - \\
\hline 9 & $8.88 \mathrm{E}+07$ & 0.7673 & $5.61 \mathrm{E}+07$ & 0.4467 & - & - \\
\hline 10 & $4.00 \mathrm{E}+07$ & 0.2109 & $9.16 \mathrm{E}+07$ & 0.8267 & - & - \\
\hline 11 & $8.43 \mathrm{E}+07$ & 0.7230 & $3.91 \mathrm{E}+07$ & 0.1284 & - & - \\
\hline 12 & $7.23 \mathrm{E}+07$ & 0.5756 & $6.34 \mathrm{E}+07$ & 0.5210 & - & - \\
\hline 13 & $1.13 \mathrm{E}+08$ & 0.8911 & $8.44 \mathrm{E}+07$ & 0.7461 & - & - \\
\hline 14 & $5.89 \mathrm{E}+07$ & 0.4494 & $1.12 \mathrm{E}+08$ & 0.8988 & - & - \\
\hline 15 & $4.45 \mathrm{E}+07$ & 0.3033 & $5.84 \mathrm{E}+07$ & 0.4702 & - & - \\
\hline 16 & - & - & $7.17 \mathrm{E}+07$ & 0.6077 & - & - \\
\hline
\end{tabular}

Table 5. Pareto solutions of problem no. 11.

\begin{tabular}{|c|c|c|c|c|c|c|}
\hline \multirow{2}{*}{$\begin{array}{l}\text { Pareto solution } \\
\text { number }\end{array}$} & \multicolumn{2}{|c|}{ NSGA-II } & \multicolumn{2}{|c|}{ NRGA } & \multicolumn{2}{|c|}{ Proposed MOHSA } \\
\hline & Objective 1 & Objective 2 & Objective 1 & Objective 2 & Objective 1 & Objective 2 \\
\hline 1 & $5.96 \mathrm{E}+10$ & 0.5760 & $9.05 \mathrm{E}+10$ & 0.8402 & $3.67 \mathrm{E}+10$ & 0.3831 \\
\hline 2 & $9.05 \mathrm{E}+10$ & 0.8280 & $7.66 \mathrm{E}+10$ & 0.7583 & $6.90 \mathrm{E}+10$ & 0.5640 \\
\hline 3 & $3.33 \mathrm{E}+10$ & 0.3466 & $3.06 \mathrm{E}+10$ & 0.4313 & $1.17 \mathrm{E}+11$ & 0.8558 \\
\hline 4 & $1.01 \mathrm{E}+11$ & 0.9133 & $7.05 \mathrm{E}+10$ & 0.7204 & $1.30 \mathrm{E}+11$ & 0.9302 \\
\hline 5 & $9.83 \mathrm{E}+10$ & 0.8903 & $1.11 \mathrm{E}+11$ & 0.9140 & $6.21 \mathrm{E}+10$ & 0.5189 \\
\hline 6 & $2.23 \mathrm{E}+10$ & 0.1907 & $3.01 \mathrm{E}+10$ & 0.4023 & $1.35 \mathrm{E}+11$ & 0.9473 \\
\hline 7 & $3.62 \mathrm{E}+10$ & 0.3727 & $5.97 \mathrm{E}+10$ & 0.6502 & $2.59 \mathrm{E}+10$ & 0.2774 \\
\hline 8 & $7.66 \mathrm{E}+10$ & 0.7161 & $8.33 \mathrm{E}+10$ & 0.7982 & $8.52 \mathrm{E}+10$ & 0.6664 \\
\hline 9 & $5.49 \mathrm{E}+10$ & 0.5357 & $6.48 \mathrm{E}+10$ & 0.6844 & $9.47 \mathrm{E}+10$ & 0.7243 \\
\hline 10 & $7.05 \mathrm{E}+10$ & 0.6660 & $5.05 \mathrm{E}+10$ & 0.5868 & - & - \\
\hline 11 & $1.21 \mathrm{E}+11$ & 0.9394 & $1.15 \mathrm{E}+11$ & 0.9177 & - & - \\
\hline 12 & $4.27 \mathrm{E}+10$ & 0.4309 & $3.93 \mathrm{E}+10$ & 0.5031 & - & - \\
\hline 13 & $1.82 \mathrm{E}+10$ & 0.1398 & $2.17 \mathrm{E}+10$ & 0.3496 & - & - \\
\hline 14 & $5.05 \mathrm{E}+10$ & 0.4982 & $1.33 \mathrm{E}+10$ & 0.2540 & - & - \\
\hline 15 & $3.06 \mathrm{E}+10$ & 0.3223 & $3.62 \mathrm{E}+10$ & 0.4779 & - & - \\
\hline 16 & $8.32 \mathrm{E}+10$ & 0.7700 & $4.64 \mathrm{E}+10$ & 0.5574 & - & - \\
\hline 17 & - & - & $9.84 \mathrm{E}+10$ & 0.8845 & - & - \\
\hline
\end{tabular}


Table 6. Computational results of multi-objective metrics comparisons for three algorithms.

\begin{tabular}{|c|c|c|c|c|c|c|c|c|c|c|c|c|c|c|c|}
\hline \multirow{2}{*}{$\begin{array}{c}\text { Problem } \\
\text { no. }\end{array}$} & \multicolumn{5}{|c|}{ Proposed MOHSA } & \multicolumn{5}{|c|}{ NSGA-II } & \multicolumn{5}{|c|}{ NRGA } \\
\hline & NOS & MID & Spacing & Diversity & Time & NOS & MID & Spacing & Diversity & Time & NOS & MID & Spacing & Diversity & Time \\
\hline 1 & 9 & $6 \mathrm{E}+06$ & 7690 & 82465023 & 11.52 & 23 & $7 \mathrm{E}+06$ & 7633 & 836454875 & 21.66 & 21 & $6 \mathrm{E}+07$ & 7655 & 648729584 & 21.99 \\
\hline 2 & 9 & $6 \mathrm{E}+06$ & 8766 & 876348278 & 15.44 & 21 & $9 \mathrm{E}+06$ & 8655 & 847638748 & 38.91 & 19 & $1 \mathrm{E}+07$ & 6544 & 772354726 & 22.73 \\
\hline 3 & 11 & $8 \mathrm{E}+07$ & 7434 & 82736292 & 16.81 & 16 & $7 \mathrm{E}+07$ & 5688 & 834768378 & 45.88 & 18 & $9 \mathrm{E}+07$ & 9853 & 827368742 & 29.91 \\
\hline 4 & 13 & $8 \mathrm{E}+07$ & 4584 & 73492284 & 21.53 & 17 & $8 \mathrm{E}+07$ & 8721 & 483784734 & 76.10 & $15:$ & $1 \mathrm{E}+08$ & 9790 & 67485282 & 49.21 \\
\hline 5 & 8 & $1 \mathrm{E}+08$ & 18712 & 873684277 & 22.73 & 21 & $6 \mathrm{E}+07$ & 87654 & 84384783 & 91.62 & 22 & $1 \mathrm{E}+08$ & 87341 & 3642347 & 82.61 \\
\hline 6 & 5 & $2 \mathrm{E}+08$ & 87645 & 784268392 & 26.72 & 21 & $2 \mathrm{E}+08$ & 77611 & 684348384 & 110.81 & 21 & $6 \mathrm{E}+08$ & 98652 & 46234827 & 121.81 \\
\hline 7 & 7 & $2 \mathrm{E}+08$ & 89966 & 374920923 & 41.94 & 15 & $3 \mathrm{E}+08$ & 54388 & 483784783 & 119.85 & 25 & $9 \mathrm{E}+08$ & 67390 & 6348232 & 129.82 \\
\hline 8 & 6 & $4 \mathrm{E}+08$ & 123560 & 374928902 & 49.66 & 15 & $5 \mathrm{E}+08$ & 876691 & 83847384 & 159.75 & 16 & $1 \mathrm{E}+09$ & 897443 & 47835404 & 148.73 \\
\hline 9 & 5 & $5 \mathrm{E}+08$ & 6588799 & 374928980 & 61.87 & 17 & $8 \mathrm{E}+08$ & 8544975 & 84384783 & 178.83 & 18 & $8 \mathrm{E}+08$ & 8756532 & 65354504 & 171.91 \\
\hline 10 & 9 & $8 \mathrm{E}+08$ & 78767221 & 238476899 & 77.99 & 16 & $9 \mathrm{E}+08$ & 87655501 & 87589979 & 233.70 & 17 & $8 \mathrm{E}+08$ & 87996209 & 67374363 & 201.74 \\
\hline 11 & 4 & $1 \mathrm{E}+09$ & 984989893 & 562437223 & 121.10 & 14 & $1 \mathrm{E}+09$ & 698212180 & 23720645 & 298.61 & 15 & $2 \mathrm{E}+09$ & 678524489 & 87373583 & 278.53 \\
\hline 12 & 3 & $3 \mathrm{E}+09$ & 6798567589 & 647289022 & 189.81 & 14 & $4 \mathrm{E}+09$ & 8974461871 & 837843878 & 412.87 & 14 & $1 \mathrm{E}+09$ & 732434588 & 54353783 & 362.74 \\
\hline
\end{tabular}

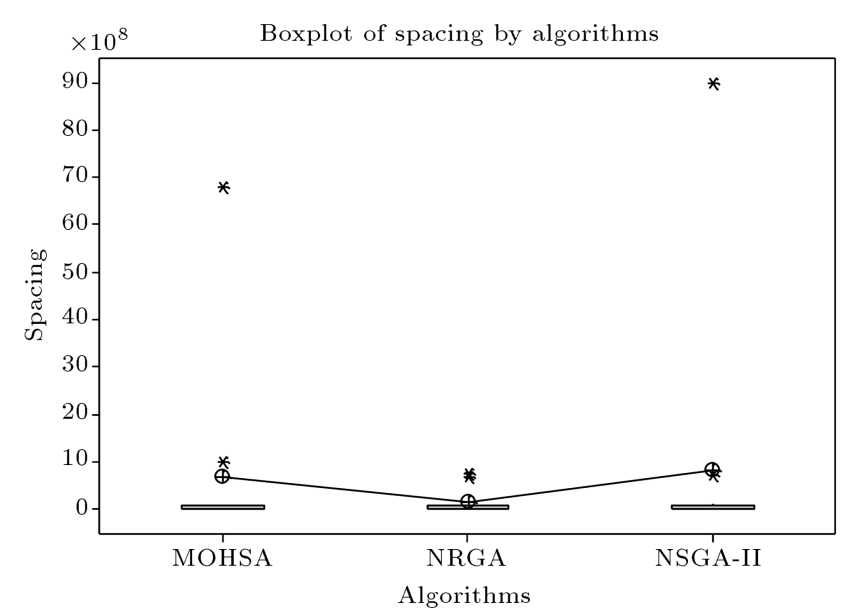

Figure 13. Box-plotcomparisons of the algorithms in terms of Spacing metric.

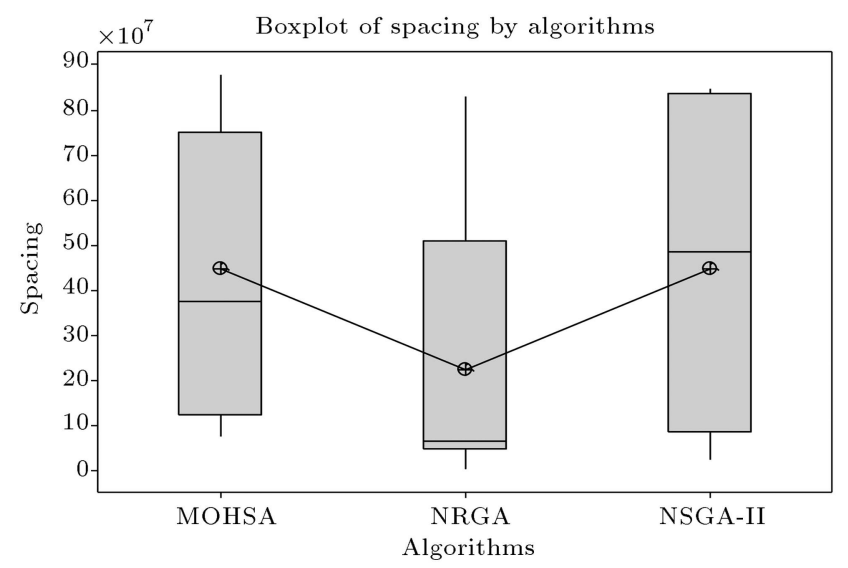

Figure 14. Box-plot comparisons of the algorithms in terms of Diversity metric.

minimize the total cost of supply chain, including inventory costs, manufacturing costs, work force costs, hiring, and firing costs, and to maximize the minimum of suppliers' reliability by considering probabilistic lead

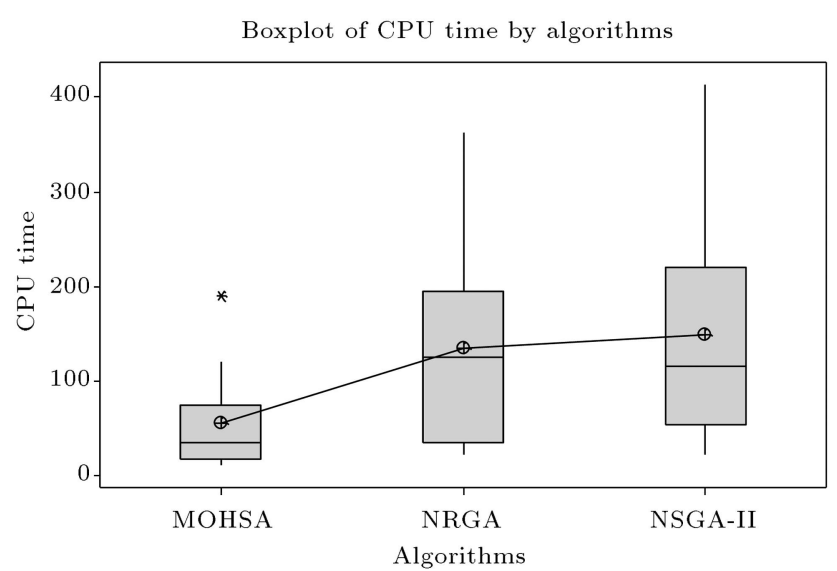

Figure 15. Box-plot comparisons of the algorithms in terms of Time metric.

Table 7. Statistical outputs of NOS metric.

\begin{tabular}{cccccc}
\hline Algorithm & DF & SS & MS & F & $P$-value \\
\hline Algorithms & 2 & 894.6 & 447.3 & 45.14 & 0.000 \\
Error & 33 & 326.83 & 9.90 & & \\
Total & 35 & 1220.89 & & & \\
\hline
\end{tabular}

times to simultaneously improve performance of the system. Since the problem is NP-Hard, a Pareto-based multi-objective harmony search algorithm is proposed. To demonstrate the performance of the presented algorithm, NSGA-II and NRGA are applied. The results show that MOHSA has better performance in terms of CPU Time. However, in terms of MID, Diversity, and Spacing metrics, our proposed MOHSA has the same capability as the best-developed algorithms in the literature. As for future research, one can develop the model by formulating the problem in competitive supply chains. 
Table 8. Statistical outputs of MID metric.

\begin{tabular}{cccccc}
\hline Algorithm & DF & SS & MS & F & $P$-value \\
\hline Algorithms & 2 & $1.43865 \mathrm{E}+17$ & $7.19323 \mathrm{E}+16$ & 0.09 & 0.910 \\
Error & 33 & $2.49970 \mathrm{E}+19$ & $7.57484 \mathrm{E}+17$ & & \\
Total & 35 & $2.51408 \mathrm{E}+19$ & & & \\
\hline
\end{tabular}

Table 9. Statistical outputs of Spacing metric.

\begin{tabular}{cccccc}
\hline Algorithm & DF & SS & MS & F & $P$-value \\
\hline Algorithms & 2 & $3.11980 \mathrm{E}+18$ & $1.55990 \mathrm{E}+18$ & 0.44 & 0.645 \\
Error & 33 & $1.15933 \mathrm{E}+20$ & $3.51313 \mathrm{E}+18$ & & \\
Total & 35 & $1.19053 \mathrm{E}+20$ & & & \\
\hline
\end{tabular}

Table 10. Statistical outputs of Diversity metric.

\begin{tabular}{cccccc}
\hline Algorithm & DF & SS & MS & F & $\boldsymbol{P}$-value \\
\hline Algorithms & 2 & $3.94541 \mathrm{E}+17$ & $1.97270 \mathrm{E}+17$ & 1.86 & 0.172 \\
Error & 33 & $3.50060 \mathrm{E}+18$ & $1.06079 \mathrm{E}+17$ & & \\
Total & 35 & $3.89514 \mathrm{E}+18$ & & & \\
\hline
\end{tabular}

Table 11. Statistical outputs of CPU Time metric.

\begin{tabular}{cccccc}
\hline Algorithm & DF & SS & MS & F & $\boldsymbol{P}$-value \\
\hline Algorithms & 2 & 62182 & 31091 & 3.35 & 0.047 \\
Error & 33 & 306463 & 9287 & & \\
Total & 35 & 368644 & & & \\
\hline
\end{tabular}

\section{References}

1. MirzapourAl-e-Hashem, S.M.J., Malekly, H. and Aryanezhad, M.B. "A multi-objective robust optimization model for multi-product multi-site aggregate production planning in a supply chain under uncertainty", In. J. Production Economics, 134, pp. 28-42 (2011).

2. Ozdamar, L., Bozyel, M.A. and Birbil S. "LA hierarchical decision support system for production planning (with case study)", European Journal of Operational Research, 104, pp. 403-422 (1998).

3. Holt, C., Modigliani, F. and Simon, H. "A linear decision rule for production and employment scheduling", Management Science, 2(1), pp. 1-30 (1955).

4. Bergstrom, G. and Smith, B. "Multi-item production planning-an extension of the HMMS rules", Management Science, 16(10), pp. 614-629 (1970).

5. Oh, H.C. and Karimi, I.A. "Global multiproduct production distribution planning with duty drawbacks", AIChE. J., 50, pp. 963-989 (2004).

6. Guillen, G., Bagajewicz, M., Sequeira, S.E., Espuna, A. and Puigjaner, L. "Management of pricing policies and financial risk as a key element for short term scheduling optimization", Ind. Eng. Chem. Res., 44, pp. 557-575 (2005).

7. Wang, R.C. and Liang T.F. "Application of fuzzy multi-objective linear programming to aggregate production planning", Computers \& Industrial Engineering, 46(1), pp. 17-41 (2004).

8. Wang, R.C. and Liang, T.T. "Aggregate production planning with multiple fuzzy goals", International Journal of Advance Manufacturing Technology, 25, pp. 589-597 (2005).

9. Leung, S.C.H. and Chan, S.S.W. "A goal programming model for aggregate production planning with resource utilization constraint", Computers \& Industrial Engineering, 56, pp. 1053-1064 (2009).

10. Baykasoglu, A. and Gocken, T. "Multi-objective aggregate production planning with fuzzy parameters", Advances in Engineering Software, 41, pp. 1124-1131 (2010).

11. MirzapourAl-e-hashem, S.M.J., Aryanezhad, M.B. and Sadjadi S.J. "An efficient algorithm to solve a multiobjective robust aggregate production planning in an uncertain environment", International Journal of Advance Manufacturing Technology, 58, pp. 765-782 (2012).

12. Sadeghi, M., Hajiagha, S.H.R. and Hashemi S.S. "A fuzzy grey goal programming approach for aggregate production planning", International Journal of $A d$ - 
vance Manufacturing Technology, 64, pp. 1715-1727 (2013).

13. Rodger, J.A. "Application of a fuzzy feasibility Bayesian probabilistic estimation of supply chain backorderaging, unfilled backorders, and customer wait time using stochastic simulation with Markov blankets", Expert Systems with Applications, 41, pp. 70057022 (2014).

14. Rodger, J.A., Pankaj, P. and Gonzalez, S.P. "Decision making using a fuzzy induced linguistic ordered weighted averaging approach for evaluating risk in a supply chain", International Journal Advanced Manufacturing Technology, 70, pp. 711-723 (2014).

15. Ramanathan, U. "Performance of supply chain collaboration - A simulation study", Expert Systems with Applications, 41, pp. 210-220 (2014).

16. Gholamian, N., Mahdavi, I., Tavakkoli-Moghaddam, R. and Nezam Mahdavi-Amiri, N. "Comprehensive fuzzy multi-objective multi-product multi-site aggregate production planning decisions in a supply chain under uncertainty", Applied Soft Computing, 37, pp. 585-607 (2015).

17. Pasandideh, S.H.R., Akhavan Niaki, S.T. and Asadi, K. "Bi-objective optimization of a multi-product multi-period three-echelon supply chain problem under uncertain environments NSGA-II and NRG", Information Sciences, 292, pp. 57-74 (2015).

18. Pasandideh, S.H.R., Akhavan Niaki, S.T. and Asadi, K. "Optimizing a bi-objective multi-period three echelon supply chain network with warehouse reliability", Expert Systems with Applications, 42, pp. 2615-2623 (2015).

19. Rooeinfar, R., Azimi, P. and Pourvaziri, H. "Multiechelon supply chain network modelling and optimization via simulation and metaheuristic algorithms", Scientia Iranica E, 23(1), pp. 330-347 (2016).

20. Entezaminia, A., Heydari, M. and Rahmani, D. "A multi-objective model for multi-product multi-site aggregate production planning in a green supply chain: Considering collection and recycling centers", Journal of Manufacturing Systems, 40(1), pp. 63-75 (2016).

21. Partovi, F. and Seifbarghy, M. "Service centers location problem considering service diversity within queuing framework", Scientia Iranica E, 22(3), pp. 1103-1116 (2015).

22. Deb, K., Pratap, A., Agarwal, S. and Meyarivan, T. "A fast and elitist multiobjective genetic algorithm: NSGA-II", IEEE Transactions on Evolutionary Computation, 6, pp. 182-197 (2002).

23. Lee, K.S. and Geem, Z.W. "A new structural optimization method based on the harmony search algorithm", Computers and Structures, 82, pp. 781-798 (2004).

24. Geem, Z.W., Kim, J.H. and Loganathan, G.V. "Harmony search optimization: application to pipe network design", International Journal of Modeling and Simulation, 22, pp. 125-133 (2002).

25. Taleizadeh, A.A., Niaki, S.T.A. and Barzinpour, F. "Multiple-buyer multiple-vendor multi-product multiconstraint supply chain problem with stochastic demand and variable lead-time: A harmony search algorithm", Applied Mathematics and Computation, 217, pp. 9234-9253 (2011).

26. Yeniay, O. and Ankare, B. "Penalty function methods for constrained optimization with genetic algorithms", Mathematical and Computational Application, 10, pp. 45-56 (2005).

27. Geem, Z.W., Kim, J.-H. and Loganathan, G.V. "A new heuristic optimization algorithm: harmony search", Simulation, 76(2), pp. 60-68 (2001).

28. Geem, Z.W. "Harmony search algorithm for solving Sudoku", In Knowledge-Based Intelligent Information and Engineering Systems, B. Apolloni, R.J. Howlett and L. Jain, Eds., KES 2007, Part I. LNCS (LNAI), 4692, pp. 371-378, Springer, Heidelberg (2007).

29. Rahmati, S.H.A., Hajipour, V. and Niaki, S.T.A. "A soft-computing Pareto-based meta-heuristic algorithm for a multi-objective multi-server facility location problem", Applied Soft Computing, 13(4), pp. 1728-1740 (2013).

30. Srinivas, N. and Deb, K. "Multi-objective function optimization using non-dominated sorting genetic algorithms", E Vol. Comput, 2(3), pp. 221-248 (1995).

31. Al Jaddan, O., Rajamani, L. and Rao, C.R. "No dominated ranked genetic algorithm for solving constrained multi-objective optimization problems", Journal of Theoretical and Applied Information Technology, 5, pp. 640-651 (2009).

32. Haupt, R.L. and Haupt, S.E., Practical Genetic Algorithms, 2nd Ed., John Wiley \& Sons (2004).

33. Chambari, A., Rahmati, S.H.R., Najafi, A.A. and Karimi, A. "A bi-objective model to optimize reliability and cost of system with a choice of redundancy strategies", Computers \& Industrial Engineering, 63, pp. 109-119 (2012).

34. Zitzler, E. and Thiele, L. "Multi-objective optimization using evolutionary algorithms: A comparative case study", In A.E. Eiben, T. Back, M. Schoenauer and H.P. Schwefel, Eds., Fifth International Conference on Parallel Problem Solving from Nature (PPSNV), PP. 292-301, Berlin, Germany (1998).

\section{Biographies}

Mohammad Ramyar is currently a PhD student at College of Industrial Engineering, Iran University of Science and research in Tehran. He obtained his MSc degree in Industrial Engineering from the Advanced Institute of Education \& Research in Mangement \& Planning in Iran (2005) and his BSc degree in Applied Mathematics from the University Shiraz in Iran (2000). 
His research interests include risk analysis and reliability in supply chain management, aggregate production planning and fuzzy sets.

Esmaeil Mehdizadeh is currently an Associate Professor at the Department of Industrial engineering, Islamic Azad University, Qazvin Branch, Iran. He received his $\mathrm{PhD}$ degree from Islamic Azad University, Science and Research Branch, Tehran in 2009, MSc degree from Islamic Azad University, South Tehran Branch in 1999, and BSc degree from Islamic Azad University, Qazvin Branch in 1996 all in Industrial Engineering. His research interests are in the areas of operation research, such as production planning, production scheduling, fuzzy sets, and meta-heuristic algorithms. He has several papers in journals and conference proceedings. Also, he is a Managing Editor of International Journal of Optimization in Industrial Engineering.

Seyyed Mohammad Hadji Molana graduated with BSC from Sharif University of Technology and with MSC and PhD from AmirKabir University of Technology in Iran. He is the Head of Industrial Engineering Department at Science and Research Branch of Islamic Azad University. His research interests are in supply chain management, advanced inventory control and production planning. 